\title{
Research Progress of Magnesium Stabilized Aluminum Titanate and New Application of It in Pigment
}

\author{
Junhua Chen', Li Yin'1, Guo Feng'2, Feng Jiang1, Qianqian Zhao', Shanfang Lan1, Mengting Liu1, \\ Feifei Zhong1, Zuzhi Huang33, Jianmin Liu², Qing Hu${ }^{1}$, Weihui Jiang1,2 \\ ${ }^{1}$ Department of Material Science and Engineering, Jingdezhen Ceramic Institute, Jingdezhen, China \\ ${ }^{2}$ National Engineering Research Center for Domestic \& Building Ceramics, Jingdezhen Ceramic Institute, Jingdezhen, China \\ ${ }^{3}$ School of Chemical Engineering and Technology, China University of Mining and Technology, Xuzhou, China \\ Email: fengguo@jci.edu.cn
}

How to cite this paper: Chen, J.H., Yin, L., Feng, G., Jiang, F., Zhao, Q.Q., Lan, S.F., Liu, M.T., Zhong, F.F., Huang, Z.Z., Liu, J.M., Hu, Q. and Jiang, W.H. (2020) Research Progress of Magnesium Stabilized Aluminum Titanate and New Application of It in Pigment. Journal of Modern Physics, 11, 1874-1890.

https://doi.org/10.4236/jmp.2020.1111117

Received: October 26, 2020

Accepted: November 21, 2020

Published: November 24, 2020

Copyright $\odot 2020$ by author(s) and Scientific Research Publishing Inc. This work is licensed under the Creative Commons Attribution International License (CC BY 4.0).

http://creativecommons.org/licenses/by/4.0/

\section{(c) (i) Open Access}

\begin{abstract}
Aluminum titanate has been widely used in low expansion applications and its thermal stability has been a hot topic. The stability of aluminium titanate research for improving product quality, and expanding its application field is of great significance. Aluminum titanate as glass melt erosion resistance and high temperature resistant, can be applied to high temperature pigment base. The medium temperature stability of aluminum titanate can be improved by ion doping, and magnesium stability of aluminum titanate has been widely studied. Therefore aluminium titanate is expected to become an ideal high temperature ceramic base material. In this paper, the preparation technology of magnesium-stabilized aluminum titanate powder was reviewed, and the preparation of magnesium-stabilized aluminum titanate powder by non-hydrolyzed sol-gel was mainly introduced.
\end{abstract}

\section{Keywords}

Aluminum Titanate, Magnesium Stabilization, Preparation Methods, Progress, Heterogeneous Condensation, Non-Hydrolyzed Sol-Gel Method

\section{Introduction}

Aluminum titanate $\left(\mathrm{Al}_{2} \mathrm{TiO}_{5}\right.$, abbreviated as $\left.A T\right)$ is characterized by high melting point $\left(1860^{\circ} \mathrm{C} \pm 10^{\circ} \mathrm{C}\right)$ and low expansion $\left(\alpha<1.5 \times 10^{-6} /{ }^{\circ} \mathrm{C}\right)$. It is a ceramic material with the best high-temperature resistance among low expansion materials (quartz glass, spodumene, cordierite and aluminum titanate). It has the characteristics of low thermal conductivity $(1.5 \mathrm{~W} / \mathrm{m} \cdot \mathrm{K})$, good thermal shock re- 
sistance, strong corrosion resistance and non-infiltration of metal and glass melt [1] [2]. Its melting point is higher than other low expansion materials, and it has a unique application in high-temperature area, so it is more and more noticed by material workers. The stable aluminum titanate can be obtained by ion doping, and the ion doping of solid solution color itself can effectively inhibit the decomposition of aluminum titanate. Therefore, aluminum titanate is expected to be an ideal new high temperature ceramic color base material. However, the crystal structure of aluminum titanate is shown in Figure 1. It can be seen that the coordination octahedrons $\left[\mathrm{AlO}_{6}\right]$ and $\left[\mathrm{TiO}_{6}\right]$ formed by $\mathrm{Al}^{3+}, \mathrm{Ti}^{4+}$ and $\mathrm{O}^{2-}$ form the structural units of aluminum titanate crystal. These octahedrons are randomly distributed and cross connected with each other in the way of common arris or common top to form the spatial network structure of aluminum titanate. However, this spatial network structure also makes the bonding in aluminum titanate layer unstable, while the interlayer bonding is relatively stable [3]. In the aluminum titanate crystal structure, the radius of $\mathrm{Al}^{3+}(0.05 \mathrm{~nm})$ is quite different from that of $\mathrm{Ti}^{4+}(0.068 \mathrm{~nm})$, while the radius of $\mathrm{O}^{2-}$ is $0.14 \mathrm{~nm}$, so the ratio of $r_{\mathrm{Al}^{3+}} / r_{\mathrm{O}^{2-}}$ is only $0.357<0.414$, and the ratio of $r_{\mathrm{Ti}^{4+}} / r_{\mathrm{O}^{2-}}$ is $0.486>0.414$. According to Paulin's rule, the distortion of $\left[\mathrm{AlO}_{6}\right]$ is larger than that of $\left[\mathrm{TiO}_{6}\right]$. At high temperature, the binding force of aluminum ion is weak, and it is easier to break away from the binding force of oxygen ion, so that the crystal structure of aluminum titanate is destroyed, leading to its decomposition [4] [5] [6]. Aluminum titanate is easy to decompose in the temperature range of $750^{\circ} \mathrm{C}-1280^{\circ} \mathrm{C}$. The thermal expansion rate of $\alpha-\mathrm{Al}_{2} \mathrm{O}_{3}$ and $\mathrm{TiO}_{2}$ is higher than that of aluminum titanate, which results in the stress concentration in the material and the increase of the thermal expansion rate so that the thermal performance of the final sintered body becomes weak and the strength decreases, which limits its wide application [7].

In order to inhibit the thermal decomposition of aluminum titanate, stabiliser additive is the most effective method [8]. Studies have shown that although

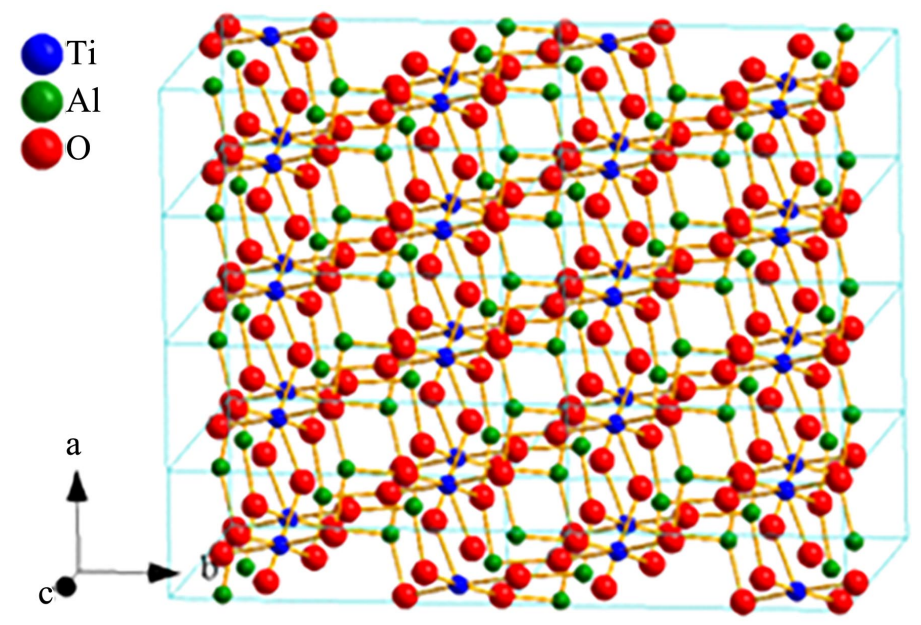

Figure 1. Crystal structure of aluminum titanate. 
$\mathrm{Fe}_{2} \mathrm{O}_{3}$ can effectively inhibit the thermal decomposition of aluminum titanate, it will reduce its strength [9]. Aluminum titanate $\left(\mathrm{Al}_{2} \mathrm{TiO}_{5}\right)$ belongs to the orbicular system and has the same structure as magnesium titanate $\left(\mathrm{MgTi}_{2} \mathrm{O}_{5}\right)$, which can form $\mathrm{Al}_{2(1-x)} \mathrm{Mg}_{x} \mathrm{Ti}_{1+x} \mathrm{O}_{5}$ solid solution. $\mathrm{MgO}$ is the most commonly used additive in the preparation of aluminum titanate [10]. An appropriate amount of $\mathrm{MgO}$ can not only partially or completely control the thermal decomposition of aluminum titanate, but also improve the mechanical properties of aluminum titanate, which has little impact on other excellent thermal properties. Therefore, stable aluminum titanate has become one of the hot spots in the research of aluminum titanate materials. At present, the main methods for preparing magnesium stabilized aluminum titanate include solid-phase method [11] [12] [13] [14] [15], co-precipitation method [16], hydrolyzed sol-gel method [17] [18] and nonhydrolytic sol-gel method [19] [20]. In this paper, the preparation methods of magnesium stabilized aluminum titanate are reviewed.

\section{Materials and Methods}

\subsection{Solid-Phase Method}

At present, the main method to prepare aluminum titanate ceramic powder is a solid-phase method. Aluminum titanate $\left(\mathrm{Al}_{2} \mathrm{TiO}_{5}\right)$ should be prepared by the solid-phase method, which mainly uses the mixture of alumina and titanium dioxide powder and makes it solid by high-temperature calcination. The advantages of this method are simple equipment, convenient operation, mature process, low cost of raw materials and suitable for mass production. However, its shortcomings are also obvious, such as high synthesis temperature, low purity, coarse particle, uniformity and particle size are difficult to be effectively controlled, resulting in poor performance and instability of the material. Moreover, aluminum titanate ceramic powders prepared by a solid-phase method often need to be crushed, ball grinding and other post-treatment to improve the morphology and properties of the particles, and the post-treatment process is complex.

The current study of aluminum titanate ceramic pigment has just started, the Italian ceramic institute professor Michele [11], such as using high temperature solid phase method at $1400^{\circ} \mathrm{C}$ was prepared by $\mathrm{M}(\mathrm{M}=\mathrm{Cr}$ (green)), $\mathrm{Mn}$ (brown), $\mathrm{Co}$ (pink) mixed with $\mathrm{Al}_{2} \mathrm{TiO}_{5}$ solid solution type ceramic pigment, the study found that $\mathrm{Cr}$ doped $\mathrm{Al}_{2} \mathrm{TiO}_{5}$ (green) and $\mathrm{Mn}$ doping $\mathrm{Al}_{2} \mathrm{TiO}_{5}$ (brown) pigment used in the glaze is still present a good shading effect, and $\mathrm{Cr}$ doped also effectively restrain the decomposition temperature of aluminium titanate. However, there are problems such as low doping concentration of color ions and Co ions dissolving out in the glaze, so the coloring effect is not ideal. The reason for this result is that the high temperature solid phase method is adopted in this study, which is limited by the uniformity of raw material mixing and solid reaction products, so it is often difficult to obtain high doping concentration and uniformity of color materials. 
Fang Qing [12] synthesized $\mathrm{Al}_{2(1-x)} \mathrm{Mg}_{x} \mathrm{Ti}_{1+x} \mathrm{O}_{5}(\mathrm{AMT})(x=0,0.01,0.05,0.1$, 0.3) solid solution powder using $\alpha-\mathrm{Al}_{2} \mathrm{O}_{3}, \mathrm{TiO}_{2}$ and $\mathrm{MgO}$ as raw materials and $\mathrm{MgO} \cdot 2 \mathrm{TiO}_{2}$ as stabilizer by solid-phase method. The raw materials of $\alpha-\mathrm{Al}_{2} \mathrm{O}_{3}$, $\mathrm{TiO}_{2}, \mathrm{MgO}$ and the mixture were put into the plastic tank; the mixture was mixed for 12 hours, dried, and pressed into shape under the pressure of 10MPa. The sample material was synthesised in solid phase in a silicon-molybdenum furnace and held at $1450^{\circ} \mathrm{C}$ for $2 \mathrm{~h}$. The powder sample was obtained after grinding after natural cooling in the furnace. The $d$ values of (200), (060) and (006) of the diffraction pattern $A T$ of sample No.1 - No.5 powder and standard sample $\alpha-\mathrm{Al}_{2} \mathrm{O}_{3}$ uniformly mixed were taken, and the accurate values were obtained after checking with the standard sample and given in Table 1 . Since aluminum titanate belongs to the rhombic crystal system and all the crystal planes taken are special ones, the three lattice constants $a, b$ and $c$ of the synthesized $\mathrm{Al}_{2(1-x)} \mathrm{Mg}_{x} \mathrm{Ti}_{1+x} \mathrm{O}_{5}$ solid solution can be simply calculated by the following three formulas.

$$
\begin{gathered}
a=h d(h 00) \\
b=k d(0 k 0) \\
c=I d(00 I)
\end{gathered}
$$

In the formula, $h, k$ and $l$ are the corresponding values in the crystal surface index. Any crystal surface can be expressed as ( $h, k$ and $l$ ), where 2, 6 and 6 are respectively.

It is found that with the increase of $x$ value in $\mathrm{Al}_{2(1-x)} \mathrm{Mg}_{x} \mathrm{Ti}_{1+x} \mathrm{O}_{5}$ solid solution, the lattice constant of solid solution increases, and the lattice constants $a, b$ and $c$ almost linearly increase, especially the linearity of $\mathrm{c}$ value is more significant. It is because the radius of $\mathrm{Mg}^{2+}(65 \mathrm{pm})$ is larger than that of $\mathrm{Al}^{3+}(51 \mathrm{pm})$ and closer to the radius of $\mathrm{Ti}^{4+}(68 \mathrm{pm})$. When $A T$ and $\mathrm{M} 2 \mathrm{~T}$ form $\mathrm{Al}_{2(1-x)} \mathrm{Mg}_{x} \mathrm{Ti}_{1+x} \mathrm{O}_{5}$ solid solution, $\mathrm{Mg}^{2+}$ enters into the lattice of $A T$ to replace part of $\mathrm{Al}^{3+}$ so that the lattice constant of AMT increases. With the increase of $\mathrm{MgO}_{2} \cdot 2 \mathrm{TiO}_{2}$ addition, the more $\mathrm{Mg}^{2+}$ enters, the more $\mathrm{Al}^{3+}$ is replaced, resulting in the linear increase of the lattice constant of AMT. The gradual increase of lattice constant further confirmed that $A T$ and $\mathrm{M} 2 \mathrm{~T}$ formed $\mathrm{Al}_{2(1-x)} \mathrm{Mg}_{x} \mathrm{Ti}_{1+x} \mathrm{O}_{5}$ solid solution, and aluminum titanate completely decomposed into $\alpha-\mathrm{Al}_{2} \mathrm{O}_{3}$ and $\mathrm{TiO}_{2}$ (rutile) without the addition of $\mathrm{MgO} \cdot 2 \mathrm{TiO}_{2}$. When $\mathrm{MgO} \cdot 2 \mathrm{TiO}_{2}$ with a mole fraction of $1 \%(x=0.01)$ was added, the diffraction peak of solid solution AMT was relatively strong. When $\mathrm{MgO} \cdot 2 \mathrm{TiO}_{2}$ with a mole fraction of $5 \%$ or $10 \%$ is added, it is basically the diffraction peak of the solid solution, indicating that $\mathrm{MgO} \cdot 2 \mathrm{TiO}_{2}$ can effectively

Table 1. $d$ values of AMT.

\begin{tabular}{cccccc}
\hline Sample & No.1 & No.2 & No.3 & No.4 & No.5 \\
\hline$d(200)$ & 1.79405 & 1.79500 & 1.80003 & 1.80146 & 1.81329 \\
$d(060)$ & 1.57385 & 1.57398 & 1.57000 & 1.58189 & 1.59086 \\
$d(006)$ & 1.60560 & 1.60612 & 1.60817 & 1.61076 & 1.62419 \\
\hline
\end{tabular}


inhibit the decomposition of aluminum titanate, resulting in good thermal stability of $\mathrm{Al}_{2(1-x)} \mathrm{Mg}_{x} \mathrm{Ti}_{1+x} \mathrm{O}_{5}$ solid solution.

Aluminum titanate is composed of $\left[\mathrm{AlO}_{6}\right]$ and $\left[\mathrm{TiO}_{6}\right]$ octahedron. Because the radius of $\mathrm{Al}^{3+}$ is smaller than that of $\mathrm{Ti}^{4+}$, $\left[\mathrm{AlO}_{6}\right]$ is a distorted octahedron. From the perspective of a chemical bond, when aluminum titanate is heated, the vibration of all atoms intensifies, but $\mathrm{Al}^{3+}$ is in a deformed octahedron, and the vibration intensifies with the rise of temperature. When the temperature rises to a certain value, the aluminum oxygen bond will break, making aluminum titanate decompose. So the more distorted $\left[\mathrm{AlO}_{6}\right]$ is, the more easily aluminum titanate will decompose. The radius of $\mathrm{Mg}^{2+}$ is larger than $\mathrm{Al}^{3+}$, which is closer to $\mathrm{Ti}^{4+}$. The replacement of $\mathrm{Al}^{3+}$ to form $\mathrm{Al}_{2(1-x)} \mathrm{Mg}_{x} \mathrm{Ti}_{1+x} \mathrm{O}_{5}$ solid solution alleviates the distortion degree of $\left[\mathrm{AlO}_{6}\right]$. Therefore, the thermal stability of $\mathrm{Al}_{2(1-x)} \mathrm{Mg}_{x} \mathrm{Ti}_{1+x} \mathrm{O}_{5}$ is higher than that of pure aluminum titanate, which is not easy to decompose. With the increase of $x$ value, the more $\mathrm{Mg}^{2+}$ replaces $\mathrm{Al}^{3+}$, the weaker the overall distortion degree in the crystal is, so the thermal stability of $\mathrm{Al}_{2(1-x)} \mathrm{Mg}_{x} \mathrm{Ti}_{1+x} \mathrm{O}_{5}$ is higher.

Zhang L.M, et al. [13] used $\alpha-\mathrm{Al}_{2} \mathrm{O}_{3}, \mathrm{TiO}_{2}$ and $\mathrm{MgO}$ to form $\mathrm{Al}_{2(1-x)} \mathrm{Mg}_{x} \mathrm{Ti}_{1+x} \mathrm{O}_{5}$ by solid reaction method at $1450^{\circ} \mathrm{C}$ for $2 \mathrm{~h}$. The lattice constants $a, b$ and $c$ of the solid solution $\mathrm{Al}_{2(1-x)} \mathrm{Mg}_{x} \mathrm{Ti}_{1+x} \mathrm{O}_{5}$ all increase linearly with the increase of $x$ value. The thermal stability of $\mathrm{Al}_{2(1-x)} \mathrm{Mg}_{x} \mathrm{Ti}_{1+x} \mathrm{O}_{5}$ was higher than that of pure aluminum titanate. The thermal stability of $\mathrm{Al}_{2(1-x)} \mathrm{Mg}_{x} \mathrm{Ti}_{1+x} \mathrm{O}_{5}$ increases with the increase of $x$ value. When $x=0.05$, the decomposition rate of $\mathrm{Al}_{2(1-x)} \mathrm{Mg}_{x} \mathrm{Ti}_{1+x} \mathrm{O}_{5}$ was only $9 \%$ at $1100^{\circ} \mathrm{C}$ for $10 \mathrm{~h}$, while the pure aluminum titanate was almost completely decomposed. With the increase of the content of M2T, the relative density of the sintered body increases, indicating that the presence of M2T is conducive to the sintering of aluminum titanate. The solid-phase method has the advantages of low cost, simple preparation process and no special equipment. However, it is difficult to produce high purity, ultra-fine and uniform aluminum titanate powder.

Buscaglia V. et al. [8] studied the effect of adding $2 \mathrm{wt} \% \mathrm{MgO}$ on reaction sintering of $\mathrm{Al}_{2} \mathrm{TiO}_{5}$. Solid reaction between $\mathrm{Al}_{2} \mathrm{O}_{3}$ and $\mathrm{TiO}_{2}$ powders with different particle sizes was studied to generate $\mathrm{Al}_{2} \mathrm{TiO}_{5}$. Aluminum titanate powder was prepared by solid-phase method from raw materials of alumina and rutile. The equal molar aluminum oxide and rutile powder were mixed, and the aluminum oxide ball and polyethylene bottle were used for wet grinding for $100 \mathrm{~h}$ in water. After drying and sieving, the obtained powder was isostatic pressed on a 150 $\mathrm{MPa}$ cylinder with diameter $=10 \mathrm{~mm}$ and length $=100 \mathrm{~mm}$. The material containing magnesium oxide was pretreated in the same manner with $2 \mathrm{wt} \%$ magnesium oxide (Aldrich, 99\%). For simplicity, when prepared with $\mathrm{Al}_{2} \mathrm{O}_{3}$ and $\mathrm{TiO}_{2}$, the sample will be displayed as $\mathrm{K}$, while the corresponding sample prepared with magnesium oxide will be displayed as KM. The results showed that the overall reaction kinetics and microstructure of the alloy varied with the increase of temperature, and the formation of pure $\mathrm{Al}_{2} \mathrm{TiO}_{5}$ was firstly nucleation and rapid growth, and then the slow transformation of unreacted oxide under 
the control of solid diffusion. The addition of $\mathrm{MgO}$ makes nucleation of the new phase easy. $\mathrm{MgAl}_{2} \mathrm{O}_{4}$ is first generated, and then the titanate solid solution particles rich in $\mathrm{Mg}$ are grown. Therefore, the final microstructure is mainly controlled by the density and size of spinel nucleus, followed by the growth process of titanate grain, leading to a strong decrease in titanate grain size and a significant increase in final density.

Synthesis [14] $\mathrm{Al}_{0.8} \mathrm{Mg}_{0.6} \mathrm{Ti}_{1.6} \mathrm{O}_{5}$ low-expansion ceramics with the same structure as aluminum titanate $\mathrm{Al}_{2} \mathrm{TiO}_{5}$ were prepared by solid reaction with $\alpha-\mathrm{Al}_{2} \mathrm{O}_{3}$, $\mathrm{MgO}$ and $\mathrm{TiO}_{2}$ rutile. The three materials were mixed according to certain stoichiometry. The mixture was ground wet in water for 24 hours, and aluminum oxide ball was added in a polyethene bottle. Three different powders were obtained by different heat treatments: 1 ) the prepared mixture (M6); 2) Burn at $1100^{\circ} \mathrm{C}$ for $2 \mathrm{~h}(\mathrm{M} 611)$ and 3) for $2 \mathrm{~h}(\mathrm{M} 613)$ at $1300^{\circ} \mathrm{C}$. M6 series corresponds to completely unreacted powder, M611 to partially reacted powder, and M613 to fully converted powder. M611 and M613 powder were burned at high temperature, then wet ground in water for 24 hours, dried and screened, and green bodies (cylinders with a diameter of $+1 \mathrm{~cm}$ and length of $+10 \mathrm{~cm}$ ) were prepared under $150 \mathrm{MPa}$ cold isostatic pressure. $\mathrm{Al}_{2} \mathrm{TiO}_{5}-\mathrm{MgTi}_{2} \mathrm{O}_{5}$ solid solution was formed from $\mathrm{M} 6$ loose powder within $0.5-7 \mathrm{~h}$ under the conditions of $1000^{\circ} \mathrm{C}$, $1100^{\circ} \mathrm{C}, 1200^{\circ} \mathrm{C}$ and $1300^{\circ} \mathrm{C}$. The sample was placed in the furnace and reached the reaction temperature within 2 - $3 \mathrm{~min}$. After the reaction, the sample was taken out of the furnace for air quenching. The results showed that $\mathrm{Al}_{0.8} \mathrm{Mg}_{0.6} \mathrm{Ti}_{1.6} \mathrm{O}_{5}$ composite material did not decompose after being annealed for 250 hours in the temperature range of $900^{\circ} \mathrm{C}-1175^{\circ} \mathrm{C}$. Sintered ceramics at $1350^{\circ} \mathrm{C}$ had a $97 \%$ relative density, a grain size of $5 \mathrm{~m}$ and an average coefficient of thermal expansion of $2 \times 10^{-6} \mathrm{~K}^{-1}$ at $80^{\circ} \mathrm{C}-1000^{\circ} \mathrm{C}$. The measured coefficient of thermal expansion was comparable to that of other oxide ceramics (e.g. standard aluminum titanate $\left(\approx 1 \times 10^{-6} \mathrm{~K}^{-1}\right)$, porous cordierite $\left(\approx 1 \times 10^{-6} \mathrm{~K}^{-1}\right)$ and lithium aluminosilicate $\left(\approx 2 \times 10^{-6} \mathrm{~K}^{-1}\right)$. The materials obtained by direct reaction sintering with the same composition had higher thermal expansion coefficient $\left(\approx 4 \times 10^{-6}\right.$ $\left.\mathrm{K}^{-1}\right)$ and showed the presence of secondary phase $\left(\mathrm{TiO}_{2}, \mathrm{Al}_{2} \mathrm{O}_{3}\right.$ and $\left.\mathrm{MgAl}_{2} \mathrm{O}_{4}\right)$.

\subsection{Microwave Sintering}

This is a new solid-phase preparation technology in recent years. Compared with the traditional solid-phase method, microwave sintering method innovatively uses gamma $\gamma-\mathrm{Al}_{2} \mathrm{O}_{3}$, which greatly improves the activity of alumina. Shahab [15] $\mathrm{Al}_{2(1-x)} \mathrm{Mg}_{x} \mathrm{Ti}_{1+x} \mathrm{O}_{5}$ ceramics prepared from $\gamma-\mathrm{Al}_{2} \mathrm{O}_{3}, \mathrm{TiO}_{2}$ and $\mathrm{MgO}$ (0, 2, 5, $7 \mathrm{wt} \%$ ). The $\gamma-\mathrm{Al}_{2} \mathrm{O}_{3}, \mathrm{TiO}_{2}$ and $\mathrm{MgO}$ nanometer powder were mixed proportionally to form the stoichiometric solid solution $\mathrm{Al}_{2(1-x)} \mathrm{Mg}_{x} \mathrm{Ti}_{1+x} \mathrm{O}_{5}$. Using alumina ball and methanol as grinding medium, the powder was ground in the plastic bottle for 2 hours to evenly mix the powder. The obtained slurry was first dried on a magnetic heater agitator and then dried in an oven at $120^{\circ} \mathrm{C}$ for 24 hours. Then sieve the dry powder to 45 mesh. A $2 \mathrm{wt} \%$ polyvinyl alcohol solution was granulated in a container for 24 hours before passing through a 45 
mesh sieve. The rectangular sample is $20 \times 6 \times 5 \mathrm{~mm}^{3}$ in a pressure of $50 \mathrm{MPa}$. At $180 \mathrm{MPa}$, the pressed sample is compacted again by cold isostatic pressure to eliminate any defects related to molding. The experimental parameters are shown in Table 2. A microwave oven ( $2.45 \mathrm{ghz}, 900 \mathrm{~W})$ was used for sintering in the temperature range of $1250^{\circ} \mathrm{C}-1400^{\circ} \mathrm{C}$. SiC crucible was used as the container, and the temperature rose to the maximum in a short time (the average heating rate was $52^{\circ} \mathrm{C} / \mathrm{min}$ ). Phase transitions are performed during sintering at different temperatures $\left(1250^{\circ} \mathrm{C}, 1350^{\circ} \mathrm{C}\right.$, and $\left.1400^{\circ} \mathrm{C}\right)$. The study found that when $X$ $=0.5$, the maximum strength of the sample was about $60 \mathrm{MPa}$. After annealing for 100 hours, the sample containing $\mathrm{MgO}$ still showed high thermal stability at $1100^{\circ} \mathrm{C}$ and formed fine crystal structure at a low temperature of $1280^{\circ} \mathrm{C}$. In addition, the addition of $\mathrm{MgO}$ reduced the formation temperature of ilmenite and had a strong effect on its microstructure. Because of the advantages of using microwave radiation, ilmenite is formed at $1250^{\circ} \mathrm{C}$ without heat preservation. However, the formation temperature of aluminum titanate using conventional heating has exceeded $1300^{\circ} \mathrm{C}$. Microwave heating reduces the formation temperature of ilmenite, but the diffusion time is insufficient due to rapid heating.

All the above preparation processes adopt the solid phase method. $\mathrm{MgO}$ is used as a magnesium source to stabilise the aluminum titanate material, to explore the properties of magnesium to stabilise the aluminum titanate. The solid-phase method has a high reaction temperature and poor uniformity of the prepared powder. Its cost is relatively low the preparation process is simple, does not need special equipment, but it is difficult to produce high purity, ultra-fine uniform powder.

\subsection{Coprecipitation Method}

The coprecipitation method overcomes the problems existing in the mixture, solid reaction and comminution of raw materials, the purity and the uniformity of composition, and the synthesis of powder raw materials with excellent properties. Coprecipitation method is to add precipitant to the mixed metal salt solution, that is, to get the evenly mixed precipitate of various components, and then conduct thermal decomposition. Compared with the solid reaction method, this method can produce a powder with good chemical uniformity and easy sintering. In common coprecipitation, all the cations in the excess precipitator solution precipitate simultaneously into a mixture. Under special circumstances,

Table 2. Samples composition with different amount of $\mathrm{MgO}$.

\begin{tabular}{cccc}
\hline Sample & $A T(\mathrm{wt} \%)$ & $\mathrm{MgO}(\mathrm{wt} \%)$ & Chemical formula \\
\hline$A T$ & 100 & 0 & $\mathrm{Al}_{2} \mathrm{TiO}_{5}$ \\
$2 A T$ & 98 & 2 & $\mathrm{Al}_{1.8} \mathrm{Mg}_{0.1} \operatorname{Ti}_{1.1} \mathrm{O}_{5}$ \\
$5 A T$ & 95 & 5 & $\mathrm{Al}_{1.4} \mathrm{Mg}_{0.3} \operatorname{Ti}_{1.3} \mathrm{O}_{5}$ \\
$7 A T$ & 93 & 7 & $\mathrm{AlMg}_{0.5} \operatorname{Ti}_{1.5} \mathrm{O}_{5}$ \\
\hline
\end{tabular}


there are precursor compounds with oxygen cation ratio meeting the requirements.

Yang [16] et al. prepared $\mathrm{Al}_{2(1-x)} \mathrm{Mg}_{x} \mathrm{Ti}_{1+x} \mathrm{O}_{5}(x=0.05$ - 0.3) composite powder by chemical coprecipitation with $\mathrm{TiCl}_{4}, \mathrm{MgCl}_{2}$ and $\mathrm{AlCl}_{3}$ aqueous solutions as raw materials, ammonia water and ammonium bicarbonate as precipitators. $\mathrm{Al}_{2} \mathrm{TiO}_{5}$ and $\mathrm{MgTi}_{2} \mathrm{O}_{5}$ crystals belong to the rhombic system, with crystal plane spacing $d_{h k l}$ and lattice constants $a, b$ and $c$. In accordance with formula $d_{h k l}=$ $1 /\left(h^{2} / a^{2}+k^{2} / b^{2}+P / c^{2}\right)$, the composite powder was prepared by co-precipitation method. By comparing the 3 -strong peak of pure $\mathrm{Al}_{2} \mathrm{TiO}_{5}$, the crystal lattice constant of the sample, and the difference value between the crystal lattice constant and pure $\mathrm{Al}_{2} \mathrm{TiO}_{5}$ could be calculated [21]. The constant lattice $c$ of $\mathrm{Al}_{2} \mathrm{TiO}_{5}$ is closely related to stability. As the $c$ value increases, the stability of $\mathrm{Al}_{2} \mathrm{TiO}_{5} \mathrm{im}$ proves, and the more the $c$ value increases, the more stable $\mathrm{Al}_{2} \mathrm{TiO}_{5}$ becomes [22]. The results show that the chemical co-precipitation method is more effective in improving the thermal stability of aluminum titanate than the solid phase method. However, the powders prepared by this method have serious agglomeration and need later treatment. $\mathrm{MgTi}_{2} \mathrm{O}_{5}$ containing $5 \%, 10 \%$ of the composite powders, with furnace cooling does not appear in the process of generation of alpha $\mathrm{Al}_{2} \mathrm{O}_{3} \mathrm{Al}_{2} \mathrm{TiO}_{5}$ decomposition, $\mathrm{TiO}_{2}$, shows that using chemical coprecipitation synthesis of powder in $\mathrm{MgTi}_{2} \mathrm{O}_{5}$ mole fraction of $5 \%$ can effectively inhibit $\mathrm{Al}_{2} \mathrm{TiO}_{5}$ thermal decomposition, and using the method of solid-phase synthesis of composite powders in $\mathrm{MgTi}_{2} \mathrm{O}_{5}$ mole fraction of $10 \% \mathrm{Al}_{2} \mathrm{TiO}_{5}$ there is still a small decomposition, which fully embodies the superiority of chemical coprecipitation.

\subsection{Sol-Gel Method}

Sol-Gel synthesis is a recently developed method which can replace the hightemperature solid-phase synthesis reaction to prepare ceramics, glass and many other solid materials. It starts from the solution of organometallic compounds or inorganic compounds, in the solution through the hydrolysis of compounds, polymerisation, from the solution into dissolved metal oxide particles of a sol, a further reaction occurs gelation. Then the gel can be heated into ceramics, glass, etc. At present, this method is one of the most important methods to prepare nano-thin films. The sol-gel method has won great interest from researchers of thin-film materials at home and abroad for its outstanding advantages.

Plinio Innocenzi [17] precursors of oxidative components were triply butanol $\left(\mathrm{Al}(\mathrm{O}-\mathrm{s}-\mathrm{Bu})_{3}\right)$, tetrply butanol $\left(\mathrm{Ti}(\mathrm{OBu})_{4}\right)$ and hexahydrate magnesium dichloride $\left(\mathrm{MgCl}_{2} \cdot 6 \mathrm{H}_{2} \mathrm{O}\right)$, using 2,4-pentanedione(acac) (Aldrich), nitric acid $\left(\mathrm{HNO}_{3}\right)$ (Prolabo) $(1 \mathrm{~N})$ and anhydrous ethanol (Carlo Erba). In order to prepare thin films composed of $\mathrm{Al}_{2} \mathrm{TiO}_{5}$ (undoped aluminum titanate), $\mathrm{Al}(\mathrm{O}-\mathrm{s}-\mathrm{Bu})_{3}$ was carefully added to reflux EtOH $\left(80^{\circ} \mathrm{C}\right)$ and $\mathrm{Ti}(\mathrm{OBu})_{4}$ was slowly added under magnetic agitation. The sol was cooled to room temperature, then $\mathrm{HNO}_{3}(1 \mathrm{~N})$ was added, and the obtained sol was stirred for $1 \mathrm{~h}$ and freshly used for impregnating coating. The preparation process of aluminum magnesium titanate was im- 
proved as follows. After adding $\mathrm{Al}(\mathrm{O}-\mathrm{s}-\mathrm{Bu})_{3}$ and $\mathrm{Ti}(\mathrm{OBu})_{4}$ into $\mathrm{EtOH}$, acac and $\mathrm{MgCl}_{2} \cdot 6 \mathrm{H}_{2} \mathrm{O}$ were introduced into EtOH. Finally, $\mathrm{HNO}_{3}$ was added to catalyse the sol. It was found that $\mathrm{Mg}_{x} \mathrm{Al}_{2(1-x)} \mathrm{Ti}_{(1+x)} \mathrm{O}_{5}$ thin films prepared by sol-gel method could produce stable aluminum titanate phase at a temperature much lower than that of solid-phase reaction. The thermal stability of the film is up to 90 hours at $1150^{\circ} \mathrm{C}$. During the long annealing time, the formation of microcracks on the surface of the film improved the heat resistance of the coating. At higher firing temperatures, $\mathrm{Mg}$ ions diffused to the surface of the film.

\subsection{Gel Injection Molding}

The equations are an exception to the prescribed specifications of this template. You will need to determine whether or not your equation should be typed using either the Times New Roman or the Symbol font (please no other font). Equations should be edited by Mathtype, not in text or graphic versions. Dai Binyu [18] prepared $\mathrm{Al}_{2(1-x)} \mathrm{Mg}_{x} \mathrm{Ti}_{1+x} \mathrm{O}_{5}$ solid solution ceramics by gel injection molding with $\alpha-\mathrm{Al}_{2} \mathrm{O}_{3}$, rutile $\mathrm{TiO}_{2}$ and $\mathrm{MgO}$ as initial powders. First, the organic monomer (methyl acrylamide) and cross-linking agent (methylene acrylamide) were dissolved in deionized water. Then, dispersant D-305 and defoaming agent C-582 were added to evenly stir to form premix. The $\mathrm{pH}$ value of premix was controlled to be $12-13$. Then mix the powder evenly according to the molar fraction ratio in Table 3 and add it into the premix to make the slurry with a solid phase volume fraction of 52\%. After ball grinding for $2.5 \mathrm{~h}$, vacuum degelling is carried out. After 15 min of treatment, appropriate amount of catalyst (tetramethylethylenediamine) and initiator (ammonium persulfate) was added to the slurry, fully stirred, and then vacuumized for $1-2 \mathrm{~min}$. Then the slurry was injected into the metal mold, dried and demodulated at $50^{\circ} \mathrm{C}$, and discharged into $1560^{\circ} \mathrm{C}$ after preservation for $2 \mathrm{~h}$ and burned.

The coefficient of thermal expansion was determined by differential method. WDW-200D microcomputer-controlled universal testing machine was used for the determination of flexural strength. The sample size was $7 \mathrm{~mm} \times 8 \mathrm{~mm} \times 60$ $\mathrm{mm}$. XRD test method was used to analyze the phase composition of sintered sample powder at $1560^{\circ} \mathrm{C}$ and its thermal decomposition performance after being kept at $1100^{\circ} \mathrm{C}$ for $50 \mathrm{~h}$. The diffraction peak area of the aluminum titanate (101) crystal plane and rutile (110) crystal plane was measured on the X-ray diffraction pattern to obtain $I_{A T}$ and $I_{T}$, and then the thermal decomposition rate of the sample was calculated according to the following formula:

Table 3. Composition design of sample.

\begin{tabular}{cccc}
\hline number & $\alpha-\mathrm{Al}_{2} \mathrm{O}_{3}$ & $\mathrm{MgO}$ & $\mathrm{TiO}_{2}$ \\
\hline 1 & 100 & 0 & 1 \\
2 & 95 & 5 & 1.05 \\
3 & 90 & 10 & 1.10 \\
4 & 85 & 15 & 1.15 \\
\hline
\end{tabular}




$$
\alpha_{A T}=\frac{I_{T}^{110}}{I_{A T}^{101}+I_{T}^{110}}
$$

It is found that the introduction of $\mathrm{MgO}$ increases the thermal stability of $\mathrm{Al}_{2} \mathrm{TiO}_{5}$, reduces the number of microcracks, and increases the density. When the amount of $\mathrm{MgO}$ is not large, the strength of $\mathrm{Al}_{2} \mathrm{TiO}_{5}$ increases with the increase of $x$ value. The coefficient of thermal expansion decreases slightly at first and then increases gradually.

\subsection{Nonhydrolytic Sol-Gel Method (NHSG)}

The nonhydrolytic sol-gel (NHSG) process simplifies the sol-gel process, in particular, homogenises the sol in the sol-gel process at the atomic level, thus greatly reducing the synthesis temperature of multi-component oxides [19] [20] [23] [24] [25] [26] [27]. NHSG method can synthesise aluminum titanate $\left(\mathrm{Al}_{2} \mathrm{TiO}_{5}\right)$ at $750^{\circ} \mathrm{C}$, which is significantly lower than the solid-phase method and traditional sol-gel method [26]. Festive aluminum titanate $\left(\mathrm{Al}_{2} \mathrm{TiO}_{5}\right)$ was prepared by the nonhydrolytic sol-gel method. However, to our knowledge, there is no formal report on the magnesium-stabilized modified aluminum titanate nonhydrolytic sol-gel (NHSG) process in the strict sense, except for the relevant patents of our research group.

Jiang Weihui et al. [19] prepared magnesium-stabilized aluminum titanate powder by nonhydrolytic sol-gel method using titanium tetrachloride and anhydrous aluminum chloride as precursors, anhydrous ethanol as oxygen supply, magnesium powder, magnesium fluoride, magnesium ethoxide and magnesium acetate as stabilizers. The effect of magnesium stabilizer on the synthesis of aluminum titanate at low temperature was studied. Anhydrous aluminum chloride $\left(\mathrm{AlCl}_{3}, \mathrm{AR}\right.$, Shanghai) and titanium tetrachloride $\left(\mathrm{TiCl}_{4}, \mathrm{AR}\right.$, Shanghai) were mixed in conical flask with anhydrous ethanol (EtOH, AR, Shanghai) as oxygen supply agent. The reaction mixture was refluxed continuously for $8 \mathrm{~h}$ at $110^{\circ} \mathrm{C}$, and aluminum titanate wet gel was obtained by nonhydrolytic sol-gel method. The wet gel was dissolved with $\mathrm{CHCl}_{3}$ solution of magnesium fluoride, magnesium powder, magnesium acetate or magnesium ethanol, refluxed at $110^{\circ} \mathrm{C}$ for $15 \mathrm{~h}$, dried and ground at $110^{\circ} \mathrm{C}$, and calcined at $750^{\circ} \mathrm{C}$ for $1.5 \mathrm{~h}$ to obtain powder samples. The powder was pressed into rods of $5 \mathrm{~mm} \times 5 \mathrm{~mm} \times 40 \mathrm{~mm}$ at a pressure of $12 \mathrm{MPa}$. Heat preservation for $20 \mathrm{~h}$ at $1100^{\circ} \mathrm{C}$ was conducted for thermal decomposition test. The results showed that the introduction of magnesium powder or magnesium fluoride could not stabilize aluminum titanate, and the failure of low temperature synthesis of aluminum titanate at $750^{\circ} \mathrm{C}$ was caused by the promotion of nonhydrolytic homogeneous condensation. In the precursor mixture, anhydrous magnesium acetate and ethoxy magnesium react with aluminol and titananol to form heterogeneous condensation bonds and promote the doping of magnesium ions into aluminum titanate lattice at $750^{\circ} \mathrm{C}$, thus improving its thermal stability. In order to study the thermal decomposition and stabilization mechanism of magnesium stabilizer to aluminum titanate, the lattice constants of samples $\mathrm{W}^{\#}, \mathrm{M}_{3}^{\#}$ and $\mathrm{M}^{\#}$ are listed in Table 4. For comparison, 
Table 4. Lattice parameters of samples.

\begin{tabular}{cccc}
\hline & \multicolumn{3}{c}{ Lattice parameter $[\mathrm{nm}]$} \\
\cline { 2 - 4 } Sample & $a$ & $b$ & $c$ \\
\hline $\mathrm{W}^{\#}$ & 0.93589 & 0.95406 & 0.36025 \\
$\mathrm{M}_{3}^{\#}$ & 0.94082 & 0.96033 & 0.35959 \\
$\mathrm{M}_{4}^{\#}$ & 0.94387 & 0.96135 & 0.35927 \\
$\mathrm{M}_{3}^{\#} \quad\left(1100^{\circ} \mathrm{C}, 20 \mathrm{~h}\right)$ & 0.94487 & 0.96613 & 0.35982 \\
$\mathrm{M}_{4}^{\#} \quad\left(1100^{\circ} \mathrm{C}, 20 \mathrm{~h}\right)$ & 0.94919 & 0.97241 & 0.36013 \\
\hline
\end{tabular}

Table 4 also gives sample lattice constants $\mathrm{M}_{3}^{\#}$ and $\mathrm{M}_{4}^{\#}$ holding $20 \mathrm{~h}$ after $1100^{\circ} \mathrm{C}$. As can be seen from Table $4, \mathrm{M}_{3}$ and $\mathrm{M}_{4}^{*}$ of the values of $a$ and $b$ are obviously about the same as $c$ than $\mathrm{W}^{\sharp}$. It is fully proved that magnesium introduced in the form of anhydrous magnesium acetate $\left(\mathrm{M}_{3}^{\#}\right)$ and ethoxylmagnesium $\left(\mathrm{M}_{4}^{\#}\right)$ has been doped into the lattice of aluminum titanate and stabilized it, which is the intrinsic reason for significantly improving the thermal decomposition ability of samples $M_{3}^{\#}$ and $M_{4}^{\#}$. After the thermal decomposition experiment held at $1100^{\circ} \mathrm{C}$ for $20 \mathrm{~h}$, the lattice constants of samples $M_{3}^{\#}$ and $M_{4}^{\#}$ further increased, indicating that magnesium ions continued to enter the lattice of aluminum titanate during the thermal decomposition process, thus improving the thermal stability of aluminum titanate. The process flow diagram 2 to be adopted in this experiment is shown in Figure 2. Heterogeneous bonding between magnesium acetate and titanium tetrachlide forms - Ti-O-Mg- and - $\mathrm{Al}-\mathrm{O}-\mathrm{Mg}$-, which promotes the doping of magnesium ions into the lattice of aluminum titanate at $750^{\circ} \mathrm{C}$, changing the lattice constant of aluminum titanate, thus improving the thermal stability of aluminum titanate.

Feng Guo et al. [20] prepared magnesium stabilized aluminum titanate powder by nonhydrolytic sol-gel method with anhydrous aluminum chloride and titanium tetrachloride as the precursor, anhydrous ethanol as the oxygen supplier, and anhydrous magnesium acetate as the stabilizer. In the glove box, no water needed for measuring low carbon alcohol in $100 \mathrm{ml}$ conical flask of dry, then put in ice water, according to the $\mathrm{TiCl}_{4}: \mathrm{AlCl}_{3}:$ Ethanol $=1: 2: 5$ (mole ratio), with a pipette measuring $\mathrm{TiCl}_{4}$, and insert a pipette conical flask quickly alcohol level in the following, slow $\mathrm{TiCl}_{4}$ mixed with alcohol, formation of $\mathrm{TiCl}_{4}$-alcohol solution, then adding anhydrous aluminum chloride, stir to mix well. 1) For unadulterated $\mathrm{W}^{\#}$ samples, reflux was directly performed at $110^{\circ} \mathrm{C}$ for $24 \mathrm{~h}$ and then dried at $110^{\circ} \mathrm{C}$ to form a dry gel; 2) For the $\mathrm{A}^{\#}$ sample introduced by anhydrous magnesium acetate before the polycondensation reaction of aluminum and titanium precursor, add $\mathrm{TiCl}_{4} 10 \mathrm{~mol} \%$ anhydrous magnesium acetate, stir evenly, reflux at $110^{\circ} \mathrm{C}$ for $24 \mathrm{~h}$, and then dry at $110^{\circ} \mathrm{C}$ to form a dry gel; 3) For the sample $\mathrm{B}^{\#}$ introduced after the condensation reaction of anhydrous magnesium acetate in the precursor of aluminum and titanium, the sample was reflux for $12 \mathrm{~h}$ at $110^{\circ} \mathrm{C}$ to form a wet gel. Then $\mathrm{TiCl}_{4} 10 \mathrm{~mol} \%$ of anhydrous magnesium acetate was added and reflux was repeated for $12 \mathrm{~h}$ at $110^{\circ} \mathrm{C}$ to form a dry gel. For 

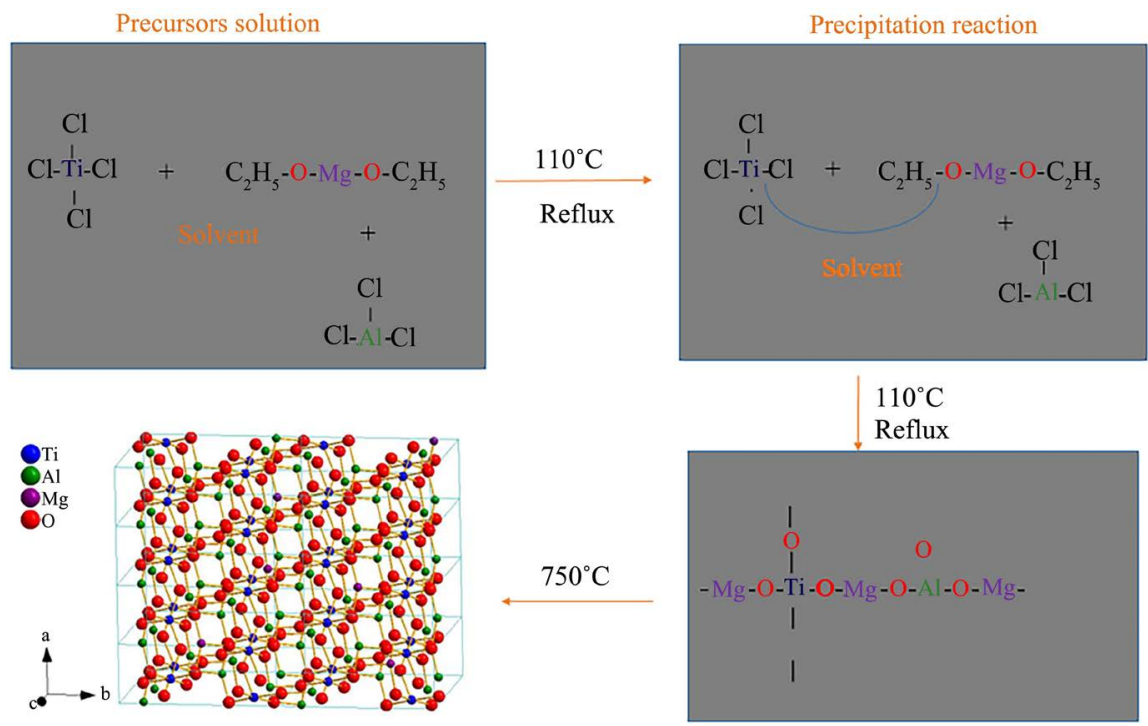

Figure 2. Schematic diagram of the process flow to be adopted in this experiment.

powder samples: the dry gel was directly obtained by calcination and grinding at $750^{\circ} \mathrm{C}$. For the test strips for thermal expansion coefficient test, the obtained dry gel was calcined at $300^{\circ} \mathrm{C}$ for $0.5 \mathrm{~h}$, then $3 \mathrm{wt} \%$ PVA was added for granulation, and then pressed into $40 \mathrm{~mm} \times 5 \mathrm{~mm} \times 5 \mathrm{~mm}$ test strips. Finally, magnesium stabilized aluminum titanate samples were obtained at $750^{\circ} \mathrm{C}$ for $1.5 \mathrm{~h}$. The anti-thermal decomposition effect was tested by holding the samples at $1100^{\circ} \mathrm{C}$ for 20 hours. The results show that the introduction of anhydrous magnesium acetate before the polycondensation of aluminum and titanium precursor is not only detrimental to the stability of aluminum titanate at low temperature, but also greatly affects the synthesis of aluminum titanate at low temperature. When introduced after the polycondensation reaction of aluminum and titanium precursor, anhydrous magnesium acetate can further deester polycondensation reaction with the polycondensation product of aluminum and titanium precursor to form heterogeneous bonding, which ensures that magnesium can enter the aluminum titanate lattice at $750^{\circ} \mathrm{C}$ to form a solid solution, thus improving its thermal stability.

Figure 3 shows the XRD pattern of the powder prepared by $750^{\circ} \mathrm{C}$ for $1.5 \mathrm{~h}$ after the addition of $\mathrm{A}^{\#}$ sample before the polycondensation of aluminum and titanium, the addition of $\mathrm{B}^{*}$ sample after the polycondensation and the addition of $\mathrm{W}^{\#}$ sample without stabilizer. It can be seen from Figure 3 that, compared with sample $\mathrm{W}^{*}$, sample $\mathrm{A}^{\#}$ not only has a significantly lower diffraction peak intensity than sample $\mathrm{W}^{\#}$, indicating that the addition of anhydrous magnesium acetate before the condensation polymerization of aluminum and titanium inhibits the low-temperature synthesis of aluminum titanate. Moreover, $A^{\#}$ sample showed a very strong corundum phase diffraction peak and a certain amount of rutile phase, and the synthesis effect of $\mathrm{A}^{*}$ sample was much worse than that of $\mathrm{A}^{\#}$ sample. The relative strength of the aluminum titanate diffraction peak of $\mathrm{B}^{\#}$ sample was also slightly reduced compared with that of $\mathrm{W}^{\#}$ sample, and there 


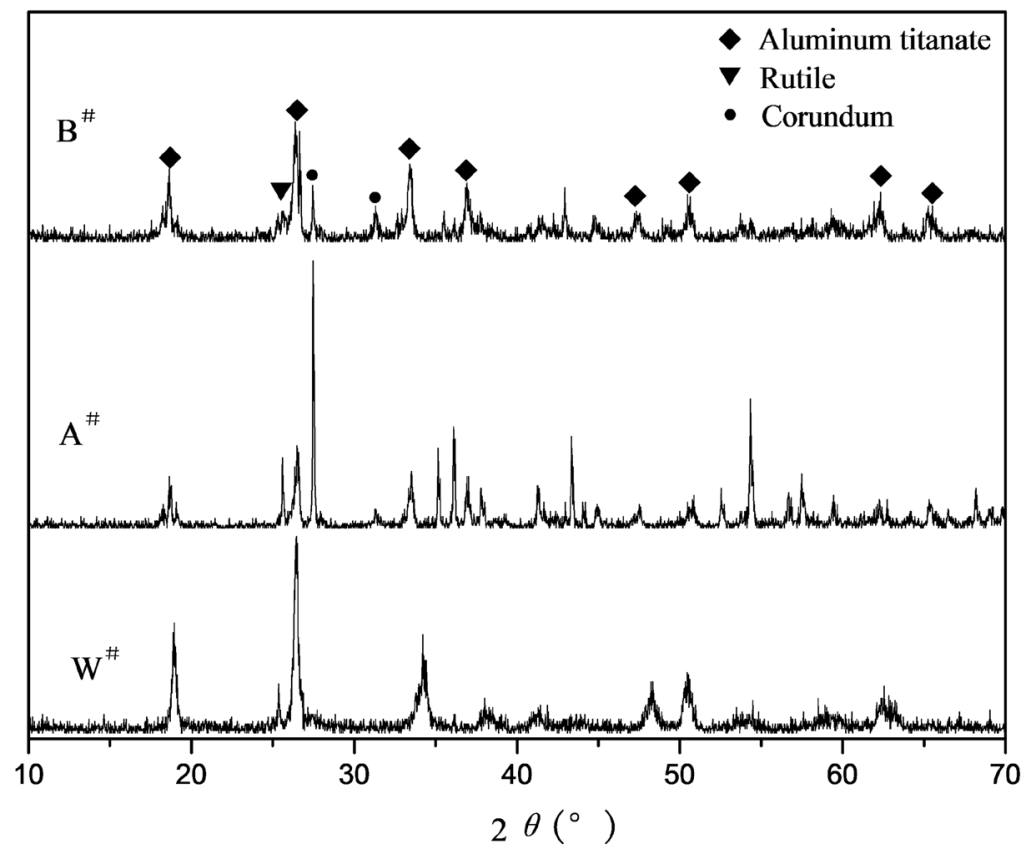

Figure 3. XRD patterns of samples $\mathrm{W}^{\#}, \mathrm{~A}^{\#}$ and $\mathrm{B}^{\#}$ treated at $750^{\circ} \mathrm{C}$ for $1.5 \mathrm{~h}$.

were a few corundum and rutile diffraction peaks, indicating that the low temperature synthesis effect of $\mathrm{B}^{*}$ sample was also slightly worse. However, compared with $A^{\#}$ sample, the synthesis effect of $B^{\#}$ sample is obviously better than $\mathrm{A}^{*}$ sample.

The thermal expansion coefficients of the three samples are listed in Table 5. It can be seen from Table 5 that the thermal expansion coefficients of samples $\mathrm{W}^{\#}$ and $\mathrm{B}^{\#}$ are very similar, both approximately equal to $1.0 \times 10^{-6} /{ }^{\circ} \mathrm{C}$, indicating that the introduction of $10 \mathrm{~mol} \%$ anhydrous magnesium acetate after the condensation polymerization of aluminum and titanium precursor does not affect the thermal expansion performance of aluminum titanate. The thermal expansion coefficient of $\mathrm{A}^{\#}$ sample introduced before the condensation polymerization of aluminum and titanium precursor was $3.67 \times 10^{-6} /{ }^{\circ} \mathrm{C}$, which was significantly higher than $0.99 \times 10^{-6} /{ }^{\circ} \mathrm{C}$ of $\mathrm{W}^{\#}$ sample. The reason is that the content of rutile phase with high expansion coefficient in $\mathrm{A}^{\#}$ sample is relatively large (see Figure 3 ), which leads to the increase of thermal expansion coefficient of $A^{\#}$ sample, while the content of rutile crystal phase in $\mathrm{W}^{\#}$ and $\mathrm{B}^{\#}$ samples is relatively low, and the content of aluminum titanate is not different, so the expansion coefficient of these two samples is very close.

Figure 4 shows the XRD patterns of $\mathrm{W}^{\#}, \mathrm{~A}^{\#}$ and $\mathrm{B}^{*}$ samples after being kept at $1100^{\circ} \mathrm{C}$ for $20 \mathrm{~h}$. The test results of their coefficient of expansion are listed in Table 6. Figure 4 shows that the sample of $\mathrm{W}^{\#}$ has been completely decomposed into the crystal phase with high expansion coefficient of corundum $(8.6 \times$ $\left.10^{-6} /{ }^{\circ} \mathrm{C}\right)$ and rutile $\left(8.0 \times 10^{-6} /{ }^{\circ} \mathrm{C}\right)$ after being kept at $1100^{\circ} \mathrm{C}$ for $20 \mathrm{~h}$, and its expansion coefficient has correspondingly increased from the initial $0.99 \times$ $10^{-6} /{ }^{\circ} \mathrm{C}$ (see Table 5) to $8.78 \times 10^{-6} /{ }^{\circ} \mathrm{C}$ (see Table 6). After being kept at $1100^{\circ} \mathrm{C}$ 
Table 5. Thermal expansion coefficients of samples treated at $750^{\circ} \mathrm{C}$ for $1.5 \mathrm{~h}$.

\begin{tabular}{cc}
\hline specimen & coefficient of thermal expansion $\left(\times 10^{-6} /{ }^{\circ} \mathrm{C}, 20^{\circ} \mathrm{C}-1000^{\circ} \mathrm{C}\right)$ \\
\hline $\mathrm{A}^{\#}$ & 3.67 \\
$\mathrm{~B}^{\#}$ & 1.13 \\
$\mathrm{~W}^{\#}$ & 0.99 \\
\hline
\end{tabular}

Table 6. Thermal expansion coefficients of samples treated at $1100^{\circ} \mathrm{C}$ for $20 \mathrm{~h}$.

\begin{tabular}{cc}
\hline Specimen & Coefficient of thermal expansion $\left(\times 10^{-6} /{ }^{\circ} \mathrm{C}, 20^{\circ} \mathrm{C}-1000^{\circ} \mathrm{C}\right)$ \\
\hline $\mathrm{A}^{\#}$ & 7.12 \\
$\mathrm{~B}^{\#}$ & 0.56 \\
$\mathrm{~W}^{\#}$ & 8.78
\end{tabular}

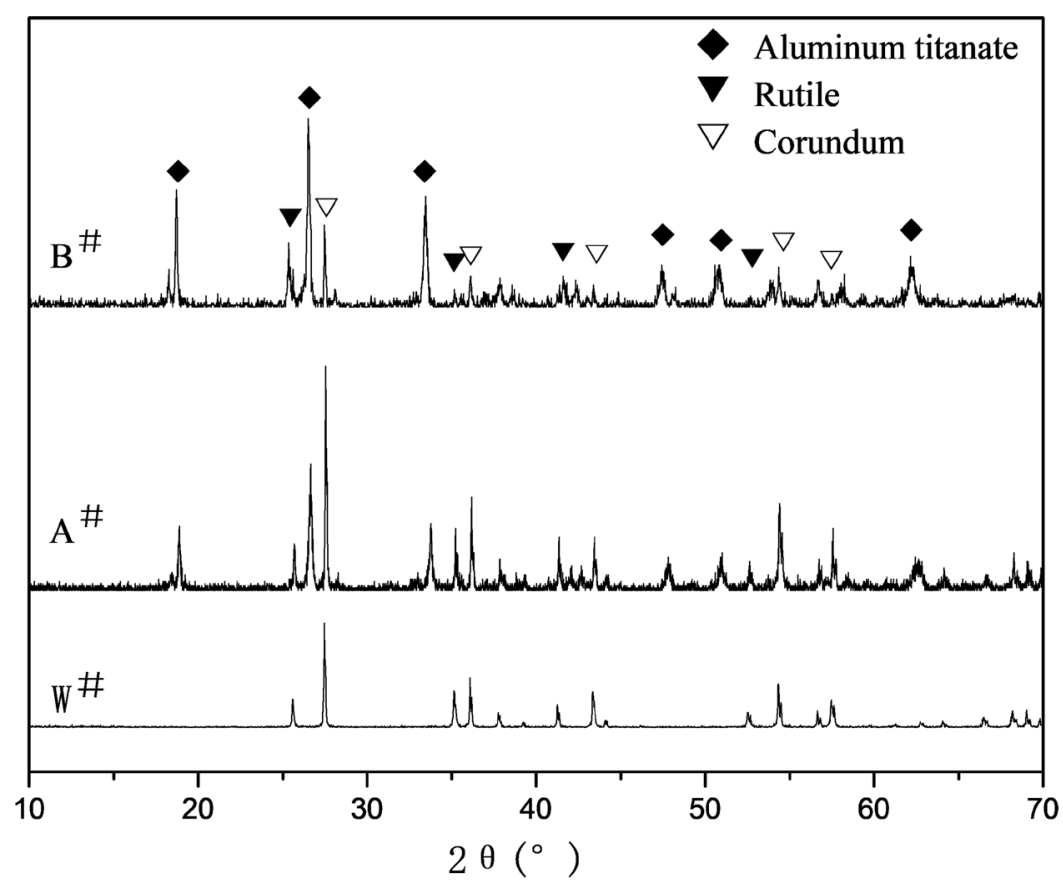

Figure 4. XRD patterns of samples $\mathrm{W}^{\#}, \mathrm{~A}^{\#}$ and $\mathrm{B}^{\#}$ treated at $1100^{\circ} \mathrm{C}$ for $20 \mathrm{~h}$.

for $20 \mathrm{~h}, \mathrm{~A}^{\#}$ was basically decomposed into rutile and corununde, and its expansion coefficient was also increased to $7.12 \times 10^{-6} /{ }^{\circ} \mathrm{C}$, indicating that the introduction of anhydrous magnesium acetate before the condensation polymerization of aluminum and titanium precursor could not effectively inhibit the thermal decomposition of aluminum titanate. However, from the increase of the thermal expansion coefficient of the sample, it can be determined that the aluminum titanate in the sample has not been completely decomposed, which is consistent with the XRD pattern corresponding to Figure 4, and there are still a small number of aluminum titanate diffraction peaks. In sharp contrast, the sample $\mathrm{B}^{\#}$ introduced after the condensation polymerization of aluminum and titanium precursor by anhydrous magnesium acetate was not decomposed by 
aluminum titanate after $20 \mathrm{~h}$ heat treatment at $1100^{\circ} \mathrm{C}$. On the contrary, compared with the XRD pattern of the sample $B^{\#}$ in Figure 4 , the synthesis effect of aluminum titanate was significantly improved, which indicated that the newly synthesized aluminum titanate phase continuously appeared in the process of the sample $\mathrm{B}^{\#}$ rising from $750^{\circ} \mathrm{C}$ to $1100^{\circ} \mathrm{C}$. Due to the increase of aluminum titanate crystalline phase and the disappearance of rutile phase, the expansion coefficient of $\mathrm{B} \#$ sample was reduced from $1.59 \times 10^{-6} /{ }^{\circ} \mathrm{C}$ to $0.56 \times 10^{-6} /{ }^{\circ} \mathrm{C}$ (see Table 6).

Thus, it can be seen that although the synthesis effect of aluminum titanate at $750^{\circ} \mathrm{C}$ is better than that of the sample of $\mathrm{B}^{\#}$, it is completely decomposed at $1100^{\circ} \mathrm{C}$ and its low expansion characteristics are completely lost. Therefore, the application of $\mathrm{W}^{\#}$ samples only outside the decomposition temperature of aluminum titanate makes sense. It is worth noting that after $1100^{\circ} \mathrm{C}$, the sample of $\mathrm{B}^{\#}$ not only shows excellent anti-decomposition ability, but also greatly improves the synthesis effect of aluminum titanate, highlighting the important value of the sample of $\mathrm{B}^{\#}$ that can be applied at the decomposition temperature of aluminum titanate, which is the purpose of improving the thermal decomposition ability of aluminum titanate.

When introduced before the polycondensation reaction of aluminum and titanium precursor, anhydrous magnesium acetate can promote the homogeneous polycondensation reaction in sol and form a large number of $\mathrm{Al}-\mathrm{O}-\mathrm{Al}$ and $\mathrm{Ti}-\mathrm{O}-\mathrm{Ti}$ bonds in gel. The low temperature synthesis of aluminum titanate at $750^{\circ} \mathrm{C}$ is seriously affected. When introducing anhydrous magnesium acetate after the polycondensation reaction of aluminum and titanium precursor, it can further deester the polycondensation reaction product of aluminum and titanium precursor to form heterogeneous bonds of $\mathrm{Mg}-\mathrm{O}-\mathrm{Al}$ and $\mathrm{Mg}-\mathrm{O}-\mathrm{Ti}$. Therefore, magnesium can enter the aluminum titanate lattice at $750^{\circ} \mathrm{C}$ to form a solid solution, thus improving its thermal stability. Of the hydrolysis of sol-gel method in preparation of aluminum titanate material literature reported less, for this, based on the team in the hydrolysis of sol-gel research of hydrolysis of heterogeneous condensation reaction conditions. The type of aluminum titanate stabilizer, the influence law and mechanism of doping effect were studied. First adopted the hydrolytic sol-gel to $750^{\circ} \mathrm{C}$ stabilization of modified aluminum titanate (reduced above $500^{\circ} \mathrm{C}$ ) than the traditional methods, both at home and abroad the first reveals the traditional anhydrous (low electronegativity) metal halide stabilizer cannot achieve aluminum titanate modified the root cause of the low temperature stabilization. Excessive ionic bond percentage (50\%) of polar compounds to the hydrolysis of heterogeneous condensation reaction. Moreover, the magnesium stabilized aluminum titanate prepared by nonhydrolytic sol-gel method has achieved negative expansion property, and the preparation process has obvious advantages.

Our research group has developed a new high temperature stable aluminum titanate base ceramic color and its preparation method. The precursor was obtained by dissolving the aluminum source, titanium source and oxygen donor in solvent. Then the colorant raw material which plays a stabilizing role or the co- 
lorant raw material and the stabilizer raw material are added together; Gel was formed by non-hydrolyzed sol-gel condensation reaction. The gel was dried, ground and calcined to obtain stabilized aluminum titanate base ceramic color. The new high-temperature stable aluminum titanate ceramic color developed by the invention has the characteristics of low synthesis temperature, low cost, small color difference and excellent coloring effect, etc., and is an ideal high-temperature color resistant material. The invention relates to a non-hydrolyzed sol-gel method for the preparation of a new stable aluminum titanate base ceramic pigment, which has the advantages of simple process, short period and easy control.

\section{Conclusion}

The preparation methods of magnesium-stabilized aluminum titanate powder have different characteristics. Magnesium stabilization improves the thermal stability of aluminum titanate. However, the temperature of non-hydrolyzed sol-gel method is relatively low, and aluminum titanate can be well synthesized at low temperature at $750^{\circ} \mathrm{C}$. Compared with the solid phase method, high-temperature reaction is required, and the powder in liquid phase method is easy to agglomerate, etc. The preparation technology of non-hydrolyzed sol-gel method has obvious advantages for the negative inflation of magnesium stable aluminum titanate materials. The synthesis of aluminum titanate powder by nonhydrolytic sol-gel method has great prospect. The medium temperature of aluminum titanate $\left(800^{\circ} \mathrm{C}-1250^{\circ} \mathrm{C}\right)$ is easy to decompose, but the poor stability of the medium temperature can be effectively inhibited by magnesium stabilization. Aluminum titanate itself has good corrosion resistance of glass melt and high temperature stability. Aluminum titanate stabilized with magnesium has good stability at medium temperature. Meanwhile, NHSG method has unique advantages. Because the non-hydrolytic heterogeneous polycondensation reaction is easy to form heterogeneous bonding and achieve uniform mixing of atomic levels, aluminum titanate stabilized with magnesium is expected to become an ideal new high-temperature ceramic color base material.

\section{Acknowledgements}

This work was supported by the National Natural Science Foundation of China [grant numbers 52072162, 51662016, 51962014]; Jiangxi Provincial Natural Science Foundation [grant numbers 20202ACBL214006, 20202ACBL214008, 20192BBEL50022, 2020ZDI03004, 20202BABL214013]. Open fund project of the Key Laboratory of Inorganic Coating Materials, Chinese Academy of Science (ICM-202001).

\section{Conflicts of Interest}

There are no conflicts to declare.

\section{References}

[1] Thomas, H.A.J. and Stevens, R. (1989) British Ceramic Transactions, 88, 144-151. 
[2] Innocenzi, P., Martucci, A. and Armelao, L. (2000) Chemistry of Materials, 12, 517-524. https://doi.org/10.1021/cm991134i

[3] Fang, Q., Zhang, L., Shen, Q., et al. (2003) Chinese Journal of Ceramics, 1, 49-53.

[4] Zhang, C. (2012) Preparation and Properties of Aluminum Titanate Ceramics. Ph.D., Ocean University of China, Qingdao.

[5] Kato, E., Daimon, K. and Takahashi, J. (1980) Journal of American Ceramics Society, 63, 355-356. https://doi.org/10.1111/j.1151-2916.1980.tb10745.x

[6] Thomas, H.A.J. and Stevens, R. (1989) British Ceramic Transactions and Journal, 88, 44-90.

[7] Korim, T. (2009) Ceramics International, 35, 1671-1675. https://doi.org/10.1016/j.ceramint.2008.07.017

[8] Buscaglia, V., Nanni, P., Battilana, G., et al. (1994) Journal of the European Ceramic Society, 13, 411-417. https://doi.org/10.1016/0955-2219(94)90018-3

[9] Jiang, W.H., Xiao, X.C., Zhou, J.E., et al. (2000) Journal of Inorganic Materials, 15, 437-440.

[10] Jiang, W.H., Xiao, X.C., Zhou, J.E., et al. (2000) Journal of Inorganic Materials, 15, 163-168.

[11] Dondi, M., Lyubenova, T.S., Carda, J.B., et al. (2010) Journal of the American Ceramic Society, 92, 1972-1980. https://doi.org/10.1111/j.1551-2916.2009.03172.x

[12] Fang, Q., Zhang, L.M. and Shen, Q. (1998) Journal of Wuhan University of Technology, 24, 44-48.

[13] Zhang, L.M. and Fang, Q. (2002) Journal of the Chinese Ceramic Society, 30, 451-455.

[14] Buscaglia, V., et al. (1997) Journal of Materials Science, 32, 6525-6531.

[15] Shadab, L. and Touradj, E. (2014) Ceramics International, 40, 12669-12674. https://doi.org/10.1016/j.ceramint.2014.04.114

[16] Yang, R., Shen, S.Y., Shen, Q., et al. (2005) China Silicate Bulletin, No. 3, 89-92.

[17] Plinio, I., Alessandro, M. and Lidia, A. (2004) Journal of the European Ceramic Society, 25, 3587-3591.

[18] Dai, B.Y. and Liu, Z.B. (2015) Special Casting and Nonferrous Alloys, 35, 453-456.

[19] Jiang, W.H., Hu, Z., Liu, J.M., et al. (2019) Ceramics International, 45, 18704-18709. https://doi.org/10.1016/j.ceramint.2019.06.096

[20] Feng, G., Jang, W.H.J.M., Liu, Q., et al. (2017) Acta Ceramica Sinica, 38, 471-475.

[21] Zhou, J.R., Zhang, Y.Z., Ma, G.H., et al. (1998) China Ceramics, 34, 1-4.

[22] Xue, M.J. and Sun, C.X. (2001) Journal of East China University of Science and Technology, 27, 76-79.

[23] Vioux, A. (1997) Chemistry of Materials, 9, 2292-2299. https://doi.org/10.1021/cm970322a

[24] Vioux, A. and Leclercq, D. (1996) Chemical Reviews, 1, 65-73. https://doi.org/10.1002/(SICI)1234-985X(199603)3:1<65::AID-HCR57>3.0.CO;2-7

[25] Hay, J.H. and Raval, H.M. (1998) Journal of Sol-Gel Science and Technology, 30, 109-112. https://doi.org/10.1023/A:1008615708489

[26] Acosta, S., Arnal, P. and Vioux, A. (1994) Materials Research Society Symposium Proceedings, 346, 43-54. https://doi.org/10.1557/PROC-346-43

[27] Jiang, W.H., Feng, G. and Liu, J.M. (2010) Acta Silicate Sinica, 38, 783-787. 